\title{
Host-Derived MCP-1 and MIP- $1 \alpha$ Regulate Protective Anti-Tumor Immunity to Localized and Metastatic B16 Melanoma
}

\author{
Yuko Nakasone, ${ }^{*}$ Manabu Fujimoto, ${ }^{*}$ \\ Takashi Matsushita, ${ }^{*}$ Yasuhito Hamaguchi, ${ }^{*}$ \\ Doanh Le Huu, ${ }^{*}$ Mizuki Yanaba, ${ }^{*}$ Shinichi Sato, ${ }^{\dagger}$ \\ Kazuhiko Takehara, ${ }^{*}$ and Minoru Hasegawa* \\ From the Department of Dermatology, * Kanazawa University \\ Graduate School of Medical Science, Kanazawa; and the \\ Department of Dermatology, ${ }^{\dagger}$ Faculty of Medicine, University of \\ Tokyo, Tokyo, Japan
}

Leukocytic infiltration into malignant melanoma lesions is tightly regulated by chemokines. To assess the role of the $\mathrm{CC}$ chemokines monocyte chemotactic protein-1 (MCP-1/chemokine ligand 2) and macrophage inflammatory protein-1 $\alpha$ (MIP-1 $\alpha$ /chemokine ligand 3) in this process, s.c. primary and metastatic B16 F10 melanoma tumor growth levels were examined in mice lacking MCP-1 or MIP-1 $\alpha$. Primary s.c. B16 F10 melanoma growth was augmented by loss of MCP-1 or MIP-1 $\alpha$. Similarly, lung metastasis was enhanced by the deficiency of MCP-1 or MIP-1 $\alpha$. Enhanced tumor outgrowth was associated with decreased percentages of infiltrating $\mathrm{CD}^{+} \mathrm{T}$ cells, $\mathrm{CD8}^{+}$ $T$ cells, and natural killer cells. In the absence of MCP-1 or MIP-1 $\alpha$, melanoma outgrowth was correlated with reduced local expression of interferon- $\gamma$, IL-6, tumor necrosis factor- $\alpha$, and transforming growth factor- $\beta$. Among these cytokines, reduced expression levels of interferon- $\gamma$ and tumor necrosis factor- $\alpha$ on leukocytes from the spleen were associated with the development of lung metastasis in chemokine-deficient mice. The local s.c. administration of these four cytokines significantly augmented another chemokine's expression and suppressed primary melanoma growth in mice deficient for MCP-1 or MIP-1 $\alpha$. The s.c. injection of MCP-1 or MIP-1 $\alpha$ significantly inhibited the primary tumor growth in wild-type mice. These results indicate that host-derived MCP-1 and MIP-1 $\alpha$ regulate protective anti-tumor immunity to B16 F10 melanoma by promoting lymphocyte infiltration into the tumor and subse- quent cytokine production. (Am J Patbol 2012, 180: 365-374; DOI: 10.1016/j.ajpath.2011.09.005)

The growth of many tumors, including melanoma, is thought to be regulated by genetic changes intrinsic to the cancer cells and by epigenetic and environmental factors. ${ }^{1}$ Although inflammation and immunotherapy can contribute to the regression of solid tumors, the relationship between tumor progression and inflammation is complex. Tumor-infiltrating lymphocytes can contribute to cancer growth and metastasis, as well as to the immunosuppression associated with malignant diseases. ${ }^{2-4}$ Furthermore, inflammatory cytokines produced by both tumor cells and tumor-infiltrating leukocytes may directly contribute to malignant progression. ${ }^{5}$ Indeed, mice lacking tumor necrosis factor (TNF)- $\alpha$ are resistant to skin carcinogenesis. ${ }^{6}$ In addition, anti-inflammatory drug use is associated with a lower incidence of tumor recurrence in colorectal cancer. ${ }^{7}$ However, inflammatory cell infiltration may also suppress tumor progression. Both natural killer (NK) cells and CD8 ${ }^{+}$cytotoxic T cells play a crucial role in anti-tumor immunity, ${ }^{8,9}$ and many studies ${ }^{10}$ have shown that $\mathrm{CD}^{+}{ }^{+} \mathrm{T}$ cells are needed in the effector phase of the anti-tumor immune response. Furthermore, tumor-associated macrophages secrete cytokines and growth factors mediating the genesis or stasis of endothelial cells, thereby inhibiting or supporting tumor progression. ${ }^{11}$

Because leukocytic infiltration and inflammation can contribute to both tumor regression and tumor progression, it is vital to understand the molecular signals that selectively promote protective anti-tumor immunity. Leukocyte infiltration is frequently observed in tumors, and a complex chemokine network in the tumor microenvironment influences the extent and phenotype of this infiltrate,

\footnotetext{
Supported by Kanazawa University.

Accepted for publication September 8, 2011

Address reprint requests to Minoru Hasegawa, M.D., Ph.D., Department of Dermatology, Kanazawa University Graduate School of Medical Science, 13-1 Takaramachi, Kanazawa, Ishikawa 920-8641, Japan. E-mail: minoruha@derma.m.kanazawa-u.ac.jp.
} 
as well as tumor cell proliferation, survival, migration, and angiogenesis. ${ }^{12,13}$ The prototypical CC chemokine, monocyte chemoattractant protein-1 (MCP-1/chemokine ligand 2), is secreted by various cell types, such as monocytes/macrophages, T lymphocytes, endothelial cells, epidermal cells, and fibroblasts. MCP-1 is a key mediator of chemotaxis and activation of CCR2-expressing macrophages. ${ }^{14,15}$ MCP-1 can also recruit NK cells and a subpopulation of $T$ lymphocytes that express high-affinity receptors, such as CCR2. Macrophage inflammatory protein-1 $\alpha$ (MIP- $1 \alpha /$ chemokine ligand 3) can be induced in several activated cell types, including macrophages, lymphocytes, dendritic cells, and endothelial cells. ${ }^{14,15} \mathrm{MIP}-1 \alpha$ can attract CCR5-bearing cells, including activated and memory T cells, monocytes/macrophages, and immature dendritic cells. MIP- $1 \alpha$ can also attract CCR 1 -expressing cells, including $\mathrm{T}$ cells and immature dendritic cells.

The involvement of chemokines in tumor progression and metastasis has been previously studied ${ }^{13,16}$; however, almost all studies have focused on chemokines secreted by the tumor cells. In this study, we examined the role of chemokines secreted by host-derived, tumorassociated cells by analyzing the s.c. growth and pulmonary metastasis of B16 F10 melanoma in mice lacking either MCP-1 or MIP- $1 \alpha$. The s.c. injection of B16 melanoma was used to model primary tumorigenesis by establishing a focus of these cells near the skin, the site of origin for melanoma. ${ }^{17}$ In contrast, tail vein injection was used to model tumor metastasis by introducing multiple tumor foci throughout the lungs. ${ }^{17}$ The results of this study suggest that host-derived MCP-1 and MIP- $1 \alpha$ regulate protective anti-tumor immunity by promoting lymphocyte infiltration into B16 melanoma lesions.

\section{Materials and Methods}

\section{Mice}

C57BL/6 wild-type mice, MCP-1 ${ }^{-1-}$ mice, ${ }^{18}$ and MIP$1 \alpha^{-1-}$ mice $^{19}$ were obtained from Jackson Laboratory (Bar Harbor, ME). Both MCP-1 ${ }^{-1-}$ mice and MIP-1 $\alpha^{-1-}$ mice were backcrossed a total of 10 times with C57BL/6J mice in the Jackson Laboratory and in our laboratory. All mice were healthy and fertile and did not display any evidence of infection or disease. Female mice, aged 9 to 12 weeks, were used for all experiments. All mice were housed in a pathogen-free barrier facility and screened regularly for pathogens. All studies and procedures were approved by the Committee on Animal Experimentation of Kanazawa University Graduate School of Medical Science (Kanazawa, Japan).

\section{B16 Melanoma Cells}

B16 F10 murine melanoma cells were obtained from American Type Culture Collection (Manassas, VA). Cells were maintained in Dulbecco's modified Eagle's medium supplemented with fetal calf serum and penicillin-streptomycin at $37^{\circ} \mathrm{C}$ in $5 \% \mathrm{CO}_{2}$. Cells were passaged twice a week with trypsin. All cell culture reagents were obtained from Sigma-Aldrich (St. Louis, MO).

\section{Primary Cutaneous Tumor Growth}

B16 cells $\left(1.5 \times 10^{6}\right)$ in $100 \mathrm{~mL}$ of PBS were injected s.c. into the shaved lateral flank of mice anesthetized by inhalation of diethyl ether. The size of the primary tumors was measured on days 7 and 14. The tumor volume was calculated using the following equation: $V=4 \pi$ $\left(L_{1} \times L_{2}^{2}\right) / 3$, where $V$ is volume $\left(\mathrm{mm}^{3}\right) ; L_{1}$, longest diameter $(\mathrm{mm})$; and $L_{2}$, shortest diameter (mm). The s.c. primary tumors were harvested, including circumference skin on day 14 after injection.

\section{Lung Metastasis}

B16 cells $\left(4 \times 10^{5}\right.$ or $1.5 \times 10^{6}$, dependent on experiments) in $100 \mathrm{~mL}$ of PBS were injected i.v. into the tail vein. The mice were sacrificed on day 14 after injection, and lungs were removed. The number of surface-visible metastatic colonies of the lungs was counted with a magnifying glass, and the mean was used for analysis. The number of colonies was counted independently by three investigators (Y. N., M. Y., and M.H.) in a blinded fashion, and the mean was used for analysis.

\section{Survival Curves}

B16 cells $\left(1.5 \times 10^{6}\right)$ in $100 \mu \mathrm{L}$ of PBS were injected i.v. into the tail vein of mice anesthetized by inhalation of diethyl ether. Deaths were recorded over a 28-day period. Postmortem dissection was performed to reveal the presence of organ metastasis other than in the lung.

\section{Histological Examination and IHC}

For immunohistochemistry $(\mathrm{IHC})$, frozen sections of the skin and lung were acetone fixed and incubated with $10 \%$ normal rabbit serum in PBS (for 10 minutes at $37^{\circ} \mathrm{C}$ ) to block nonspecific staining. Sections were then incubated with rat monoclonal antibody (Ab) specific for mouse CD3 (AbD Serotec, Oxford, UK), CD4, CD8, CD11b (BD PharMingen, San Diego, CA), F4/80, NK1.1 (BioLegend, San Diego), and American hamster monoclonal Ab specific for mouse CD11c (BioLegend). Rat IgG (Southern Biotechnologyassociates Inc., Birmingham, AL) was used as a control for nonspecific staining. Sections were incubated sequentially (for 20 minutes at $37^{\circ} \mathrm{C}$ ) with a biotinylated goat anti-rat IgG (BD PharMingen) or a goat anti-American hamster IgG (BioLegend) secondary $\mathrm{Ab}$ and then horseradish peroxidase-conjugated avidin-biotin complexes (Vectastain ABC method; Vector Laboratories, Burlingame, CA). Sections were developed with $3,3^{\prime}$-diaminobenzidine tetrahydrochloride and hydrogen peroxide, and then counterstained with methyl green. Stained cells were counted in five random grids under a high-power microscopic field (original magnification, $\times 400$ ) on a light microscope. Each section was examined independently by three investigators 
(Y.N., M.Y., and M.H.) in a blinded fashion, and the mean was used for analysis.

\section{Real-Time PCR}

Total RNA was isolated from frozen s.c. skin tumors, lung tissues with QIAGEN RNeasy spin columns (QIAGEN Ltd, Crawley, UK). Also, total RNA was extracted from $\mathrm{CD} 4^{+}$ $\mathrm{T}$ cells, $\mathrm{CD} 8^{+} \mathrm{T}$ cells, NK cells, and $\mathrm{CD} 11 \mathrm{~b}^{+}$macrophages isolated from the spleen and peripheral lymph nodes (axillar and inguinal) by magnetic beads (CD4 ${ }^{+}$, $\mathrm{CD}^{+}$, NK; negative selection, CD11 $\mathrm{b}^{+}$; positive selection; MiltenyiBiotec, Bergisch Gladbach, Germany). Total RNA was then reverse transcribed into cDNA according to the protocol of the Reverse Transcription System (Promega, Madison, WI). The expression of interferon (IFN)- $\gamma$, IL-2, IL-4, IL-6, IL-10, IL-12/23 (p40), MCP-1, MIP- $1 \alpha$, TNF- $\alpha$, and transforming growth factor (TGF)- $\beta$ mRNA was analyzed using a real-time PCR quantification method, according to the manufacturer's instructions (Applied Biosystems, Foster City, CA). Sequence-specific primers and probes were designed by Pre-Developed TaqMan Assay Reagents (Applied Biosystems). Real-time PCR (one cycle of $50^{\circ} \mathrm{C}$ for 2 minutes and $95^{\circ} \mathrm{C}$ for 10 minutes and 40 cycles of $92^{\circ} \mathrm{C}$ for 15 seconds and $60^{\circ} \mathrm{C}$ for 60 seconds) was performed on an $\mathrm{ABI}$ Prism 7000 Sequence Detector (Applied Biosystems). Glyceraldehyde-3-phosphate dehydrogenase (GAPDH) was used to normalize mRNA. To compare target gene with housekeeping GAPDH gene mRNA expression, the relative expression of real-time PCR products was determined using the $\Delta \Delta \mathrm{C}_{\mathrm{T}}$ method. ${ }^{20}$ The fold induction = $2^{-\Delta \Delta C_{T}}$, where $C_{T}$ is the threshold cycle (ie, the cycle number at which the sample's relative fluorescence increases about the background fluorescence and $\Delta \Delta \mathrm{C}_{\mathrm{T}}=$ $\left[\mathrm{C}_{\mathrm{T}}\right.$ gene of interest (unknown sample) $-\mathrm{C}_{\mathrm{T}} \mathrm{GAPDH}$ (unknown sample)] - $\left[\mathrm{C}_{\mathrm{T}}\right.$ gene of interest (calibrator sample) $\mathrm{C}_{\mathrm{T}} \mathrm{GAPDH}$ (calibrator sample)]). Each sample was run in duplicate, and the mean $\mathrm{C}_{\mathrm{T}}$ was used in the equation.

\section{Cytokine Injection}

B16 cells $\left(1.5 \times 10^{6}\right)$ in $100 \mu \mathrm{L}$ of PBS were injected s.c. into the shaved lateral flank of mice anesthetized by inhalation of diethyl ether. Six hours after transfer of B16 cells, recombinant cytokines [1.0 to $1.5 \mu \mathrm{g}$ of MCP-1, MIP-1 $\alpha$ (ProSpec-Tany Technogene, East Brunswick, NJ), IFN- $\gamma$, IL-6, TGF- $\beta$, and TNF- $\alpha$ (R\&D Systems, Minneapolis, MN)] were injected S.c. at the same location, and the injection of those cytokines was continued every other day for the duration of the experiment. The size of s.c. tumors was measured on day 14. The s.c. tumors were harvested, including circumference skin on day 14 after injection of B16 cells.

\section{Statistical Analysis}

The Mann-Whitney U-test was used for determining the level of significance of differences in sample means, and the Bonferroni's test was used for multiple comparisons.
Survival analysis was performed using a Kaplan-Meier estimate.

\section{Results}

\section{Augmentation of Primary Tumor Growth in the Absence of MCP-1 or MIP-1 $\alpha$}

To evaluate the effect of the loss of MCP-1 and/or MIP- $1 \alpha$ on primary tumor growth, B16 melanoma cells were injected s.c. into mice lacking MCP-1 or MIP- $1 \alpha$. In both genotypes, the implanted B16 melanoma cells formed solid round tumors with well-defined margins on the lateral flank. The tumor size was determined on days 7 and 14 (Figure 1A). There were no significant differences in tumor size among the groups of mice on day 7 . On day 14 , the tumor volume in $\mathrm{MCP}-1^{-1-}$ and MIP- $1 \alpha^{-1-}$ mice was $44.0 \%$ $(P<0.05)$ and $57.8 \%(P<0.01)$ greater, respectively, than that in wild-type mice. However, a significant difference was not observed between MCP-1 $1^{-1-}$ mice and MIP- $1 \alpha^{-1-}$ mice. Metastatic colonies in the lungs or other organs were not found among any of the groups of mice on day 14 . Thus, primary tumor growth was augmented by the absence of MCP-1 or MIP- $1 \alpha$ expression.

\section{Enhancement of Pulmonary Metastasis in the Absence of MCP-1 or MIP-1 $\alpha$}

To assess the effect of the loss of chemokines on pulmonary metastasis, B16 melanoma cells $\left(4 \times 10^{5}\right)$ were injected via the tail vein into chemokine-deficient mice. The cells formed metastatic colonies in the lungs of each genotype of mice. After 14 days, the metastatic tumors appeared as black pigmented colonies, increased to 1 to $2 \mathrm{~mm}$ in diameter, and tended to fuse each other. The loss of both MCP- 1 and MIP- $1 \alpha$ resulted in a significant 89\% $(P<0.001)$ and $76 \%(P<0.001)$ increase, respectively, in the number of metastatic nodules relative to wild-type mice (Figure 1B). Thus, the absence of MCP-1 or MIP- $1 \alpha$ resulted in augmented pulmonary metastasis.

\section{Loss of Either MCP-1 or MIP-1 $\alpha$ Reduces Survival}

To determine the role of MCP- 1 and MIP- $1 \alpha$ in animal survival after tumor cell challenge, B16 melanoma cells $(1.5 \times$ $10^{6}$ ) were injected via the tail vein into wild-type and chemokine-deficient mice, and mortality was recorded over a 28day period. The survival period was significantly reduced in MCP-1 ${ }^{-1-}(P<0.05)$ or MIP-1 $\alpha^{-1-}(P<0.01)$ mice relative to wild-type mice (Figure 2). Postmortem analysis indicated that metastases were limited to the lung. These results confirmed the rapid lung metastasis of melanoma in the absence of either MCP- 1 or MIP- $1 \alpha$.

\section{Reduced Leukocytic Infiltration in MCP-1- or MIP-1 $\alpha$-Deficient Mice}

To determine which leukocyte subsets were affected by the loss of these chemokines, an IHC analysis was per- 
A
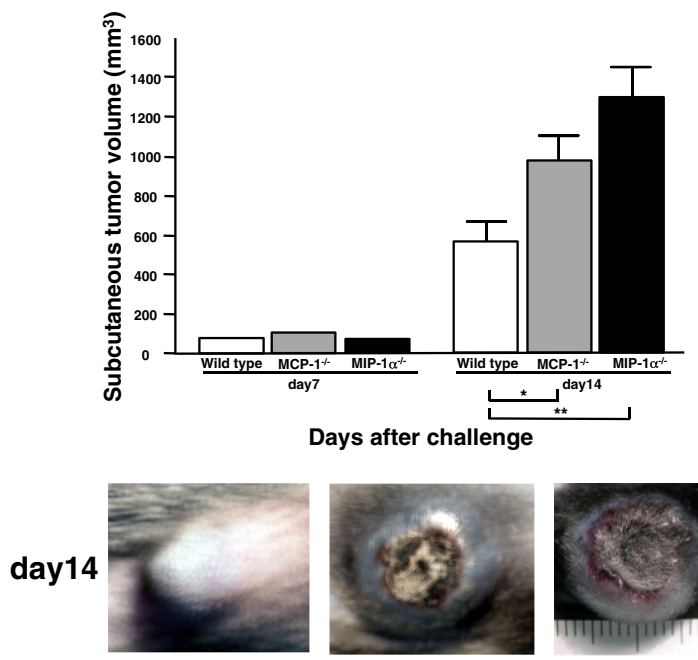

Wild type

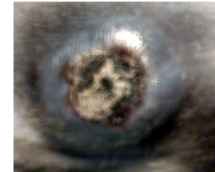

MCP-1\%

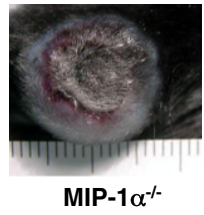

B

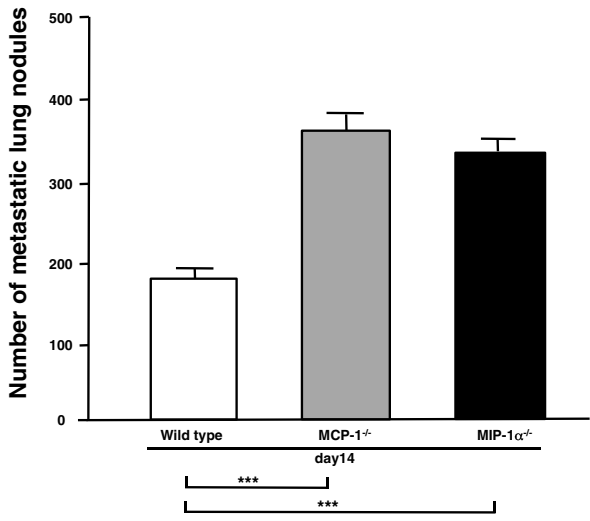

day14

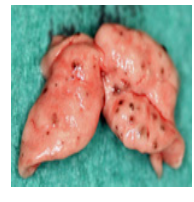

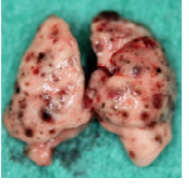

MCP-1-

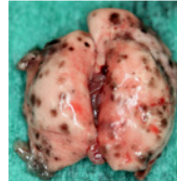

MIP-1 $\alpha^{-1-}$

Figure 1. A: The s.c. primary growth of B16 F10 melanoma in $\mathrm{MCP}-1^{-/-}$, MIP- $1 \alpha^{--}$, and wild-type mice. B16 F10 melanoma cells $\left(1.5 \times 10^{6}\right)$ were injected s.c. On days 7 and 14, the size of the primary tumors was determined. These results were obtained from 10 mice in each group. Representative pictures of primary tumors on day 14 are also shown. B: Pulmonary metastasis of B16 F10 melanoma in MCP-1 ${ }^{-/-}$, MIP- $1 \alpha^{-/-}$, and wild-type mice. B16 F10 melanoma cells $\left(4 \times 10^{5}\right)$ were injected i.v. into the tail vein; after 14 days, the lungs were removed. To evaluate the pulmonary metastasis, the number of surface-visible metastatic colonies of the lungs was counted with a magnifying glass, and the mean was used for analysis. These results were obtained from seven mice in each group. Representative metastatic nodules lacking MCP-1 or MIP-1 $\alpha$ and wild-type mice are also shown. All values represent the mean \pm SEM. ${ }^{*} P<0.05,{ }^{* * *} P<0.01$, and ${ }^{* * * * * *} P<0.001$.

formed on the s.c. primary and metastatic tumors 14 days after melanoma cell $\left(1.5 \times 10^{6}\right)$ challenge. Although the numbers of $\mathrm{CD}^{+}$and $\mathrm{CD}^{+} \mathrm{T}$ cells in s.c. tumors were decreased in $\mathrm{MCP}-1^{-1-}$ mice compared with wild-type mice, the difference was not significant (Figure 3A). However, the numbers of $\mathrm{CD}^{+}$and $\mathrm{CD}^{+} \mathrm{T}$ cells infiltrating s.c. tumors were significantly reduced in MIP- $1 \alpha^{-1-}$ mice relative to wild-type mice $(P<0.01)$. Both $\mathrm{MCP}_{-1} 1^{-1-}$ mice and MIP- $1 \alpha^{-/-}$mice had significantly decreased numbers of infiltrating $\mathrm{CD}^{-} \mathrm{NK} 1.1^{+} \mathrm{NK}$ cells compared with wild-type mice $(P<0.01)$. The numbers of $\mathrm{CD} 11 \mathrm{~b}^{+} \mathrm{F} 4 / 80^{+}$macrophages, CD11 ${ }^{+} \mathrm{F} 4 / 80^{+}$macrophages, and $\mathrm{CD}^{+} \mathrm{NK} 1.1^{+} \mathrm{NKT}$ cells present in s.c. tumors were comparable between each genotype.

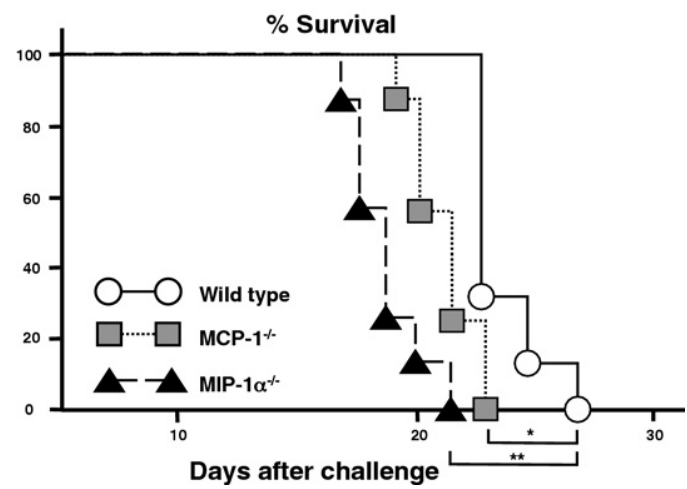

Figure 2. Effect of loss of MCP-1 or MIP- $1 \alpha$ on survival after i.v. injection of B16 F10 melanoma cells. Mice were injected i.v. with B16 F10 melanoma cells $\left(1.5 \times 10^{6}\right)$ and observed for 28 days. These results were obtained from 10 mice in each group. Survival was significantly reduced in $\mathrm{MCP}-1^{-1-}$ or MIP- $1 \alpha^{->-}$mice relative to wild-type mice. ${ }^{*} P<0.05,{ }^{* *} P<0.01$.
In tumor-bearing lungs, the number of $\mathrm{CD}^{+} \mathrm{T}$ cells was significantly reduced in $\mathrm{MCP}-1^{-1-}$ mice and MIP$1 \alpha^{-1-}$ mice relative to wild-type mice $(P<0.01)$ (Figure 3B). Similarly, $\mathrm{CD}^{+} \mathrm{T}$ cells were significantly reduced in MCP-1 $1^{-1-}$ mice and MIP- $1 \alpha^{-1-}$ mice relative to wild-type mice $(P<0.01)$. CD11 ${ }^{+} \mathrm{F} 4 / 80^{+}$macrophages were significantly reduced in $\mathrm{MCP}-1^{-1-}$ mice and $\mathrm{MIP}-1 \alpha^{-1-}$ mice relative to wild-type mice $(P<0.05)$, although the number of $\mathrm{CD} 11 \mathrm{~b}^{+} \mathrm{F} 4 / 80^{+}$macrophages was not significantly different among each strain. The number of CD3 ${ }^{-} \mathrm{NK} 1.1^{+} \mathrm{NK}$ cells was significantly reduced in both $\mathrm{MCP}-1^{-1-}$ mice and MIP- $1 \alpha^{-1-}$ mice relative to wild-type mice $(P<0.05)$, although the number of $\mathrm{CD} 3^{+} \mathrm{NK} 1.1^{+}$ NKT cells was similar among each strain. Collectively, these results show that augmented outgrowth of primary and metastatic melanoma lesions was associated with reduced lymphocyte infiltration.

\section{Local Cytokine mRNA Expression Is Reduced in the Absence of MCP-1 and MIP-1 $\alpha$}

The production of proinflammatory cytokines by infiltrating leukocytes plays a critical role in the modulation of the immune response to a tumor. ${ }^{21}$ To determine the role of CC chemokines in cytokine expression during tumor development, cytokine mRNA from wild-type and chemokine-deficient s.c. tumors (Figure 4A) and pulmonary metastases (Figure 4B) were measured by real-time PCR. In s.c. tumors, IFN- $\gamma$ mRNA levels were significantly decreased in MIP- $1 \alpha^{-1-}$ mice $(P<0.05)$ but not in MCP$1^{-1-}$ mice compared with wild-type mice. $\mathrm{MCP}-1^{-1-}$ mice, but not MIP-1 $\alpha^{-/-}$mice, exhibited significantly re- 
A
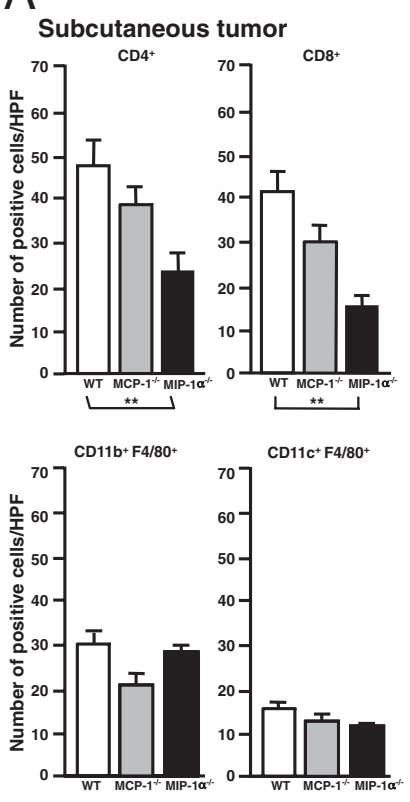

B
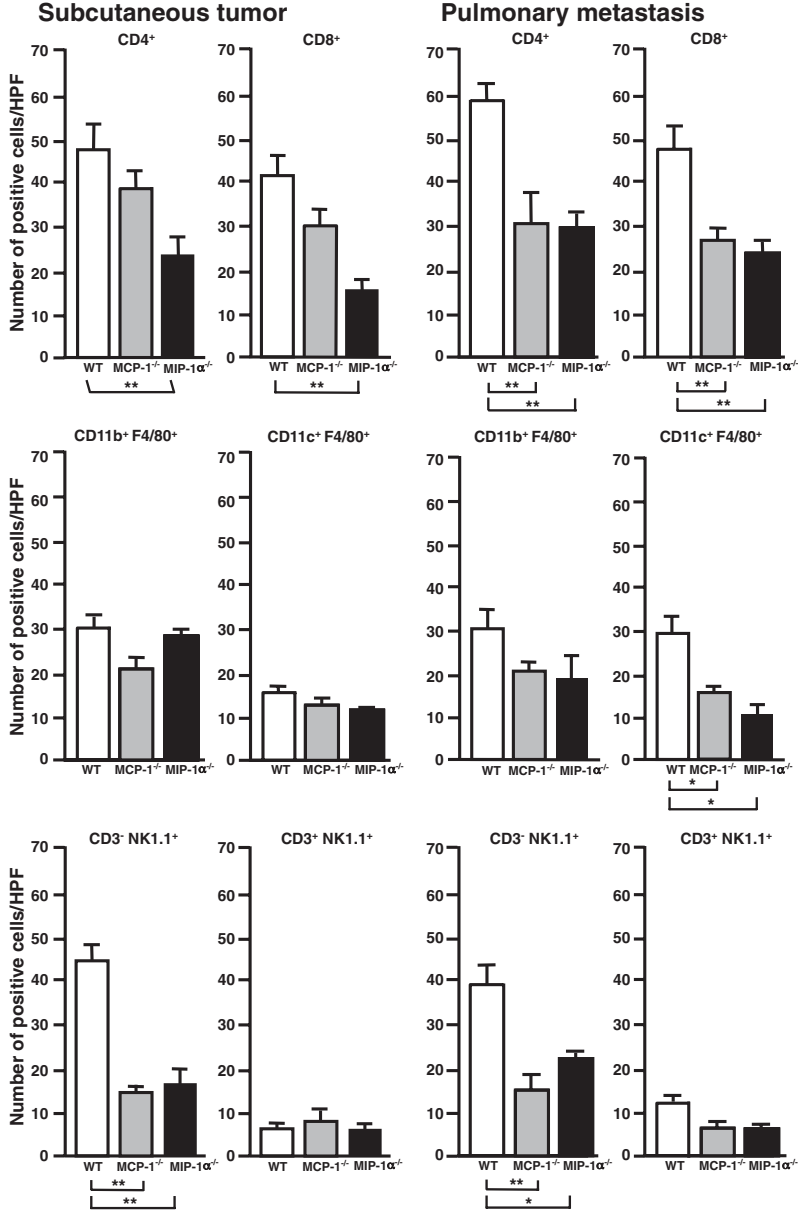

Figure 3. The accumulation of $\mathrm{CD}^{+}{ }^{+} \mathrm{T}$ cells, $\mathrm{CD}^{+}{ }^{+} \mathrm{T}$ cells, $\mathrm{CD} 11 \mathrm{~b}^{+} \mathrm{F} 4 / 80^{+}$ macrophages, $\mathrm{CD} 11 \mathrm{c}^{+} \mathrm{F} 4 / 80^{+}$macrophages, $\mathrm{CD} 3^{-} \mathrm{NK} 1.1^{+} \mathrm{NK}$ cells, and $\mathrm{CD}^{+} \mathrm{NK} 1.1^{+}$NKT cells at the site of the s.c. tumors (A) or pulmonary metastatic tumors (B) of MCP-1 ${ }^{-/-}$, MIP- $1 \alpha^{-/-}$, and wild-type (WT) mice 14 days after the s.c. or i.v. injection of B16 F10 melanoma cells $\left(1.5 \times 10^{6}\right)$. $\mathrm{CD}^{+}{ }^{+} \mathrm{T}$ cells, $\mathrm{CD}^{+} \mathrm{T}$ cells, CD $11 \mathrm{~b}^{+}$macrophages, CD $11 \mathrm{c}^{+}$macrophages, NK cells, and NKT cells were detected by IHC, and the numbers of each were determined in one high-power microscopic field $\left(0.07 \mathrm{~mm}^{2}\right)$ in sections from the skin and lung. These results were obtained from 10 mice in each group. All values represent the mean \pm SEM. ${ }^{*} P<0.05$, ${ }^{* * *} P<0.01$

duced IL-6 mRNA levels compared with wild-type mice $(P<0.05)$. TNF- $\alpha$ mRNA levels were decreased in both $\mathrm{MCP}-1^{-1-}$ and MIP- $1 \alpha^{-1-}$ mice relative to wild-type mice $(P<0.05)$. TGF- $\beta$ mRNA levels were also significantly decreased in $\mathrm{MCP}-1^{-1-}$ and $\mathrm{MIP}-1 \alpha^{-/-}$mice relative to wild-type mice $(P<0.05$ and $P<0.01$, respectively).

Unlike in the primary tumor, significantly reduced IFN- $\gamma$ mRNA levels were observed in lung metastases from $\mathrm{MCP}-1^{-1-}$ mice $(P<0.01)$ but not in MIP-1 $\alpha^{-/-}$mice. IL-6 mRNA levels were comparable in $\mathrm{MCP}_{-1} 1^{-/-}$mice and wild-type mice, but were significantly decreased in MIP- $1 \alpha^{-1-}$ mice relative to wild-type mice $(P<0.01)$. TNF- $\alpha$ expression levels in the lung were comparable between each genotype. TGF- $\beta$ expression was significantly decreased in MIP-1 $\alpha^{-1-}$ mice $(P<0.01)$ but not in MCP-1 ${ }^{-1-}$ mice, relative to wild-type mice.

mRNA expression levels of IL-2, IL-4, IL-10, and IL12/23 ( $p 40$ ) were comparable between each genotype in both s.c. tumor and lung metastasis (data not shown). Thus, reduced expression levels of IFN- $\gamma$, IL-6, TNF- $\alpha$, and TGF- $\beta$ were found in the primary tumor and lung metastatic tissues of $\mathrm{MCP}_{-} 1^{-1-}$ and $\mathrm{MIP}-1 \alpha^{-1-}$ mice.

\section{Reduced mRNA Expression of IFN- $\gamma$ and \\ TNF- $\alpha$ on Leukocytes from MCP-1- or \\ MIP-1 $\alpha$-Deficient Mice}

Cytokine mRNA expression was evaluated on $\mathrm{CD}^{+}{ }^{+} \mathrm{T}$ cells, CD8 ${ }^{+}$T cells, CD11 $\mathrm{b}^{+}$macrophages, and NK cells isolated by magnet beads from the spleen and peripheral lymph nodes of $\mathrm{MCP}-1^{-1-}, \mathrm{MIP}-1 \alpha^{-1-}$, and wild-type mice at 14 days after the i.v. melanoma $\left(1.5 \times 10^{6}\right)$ injection. The mRNA levels of IFN- $\gamma, \mathrm{IL}-6, \mathrm{TNF}-\alpha$, and TGF- $\beta$ were measured by real-time PCR (Figure 5). In general, IFN- $\gamma$ and TNF- $\alpha$ expression levels were remarkably increased in each leukocyte subset of spleen after the injection of melanoma. Deficiency of MCP-1 or $\mathrm{MIP}-1 \alpha$ significantly reduced these cytokine expression levels. A similar tendency was found in a part of a leukocyte subset from peripheral lymph nodes, but the tendency of lymph nodes was not so clear compared with that of spleen. Expression levels of IL-6 or TGF- $\beta$ were increased or decreased according to the leukocyte subset of spleen and lymph nodes after melanoma injection. Loss of MCP-1 or MIP- $1 \alpha$ showed no constant effects on the expression levels of IL-6 or TGF- $\beta$. These findings indicate that reduced expression levels of IFN- $\gamma$ and TNF- $\alpha$ on leukocytes from spleen are associated with the augmented melanoma outgrowth in chemokine-deficient mice.

\section{The Subcutaneous Injection of MCP-1 or MIP- $1 \alpha$ Inhibits the Development of Primary Tumors}

To confirm the direct effect of MCP-1 and MIP-1 $\alpha$ for melanoma development, recombinant MCP-1 or MIP- $1 \alpha$
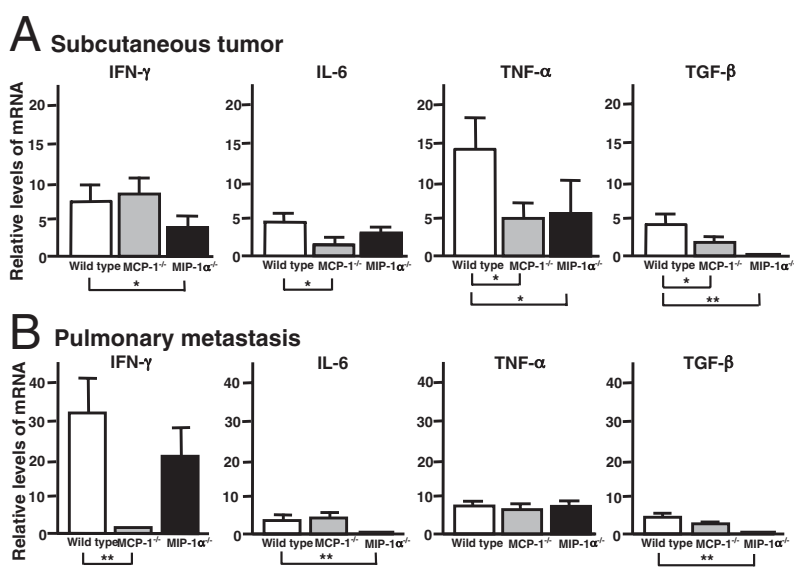

Figure 4. Cytokine mRNA expression in the s.c. or pulmonary metastatic tumor of MCP-1 ${ }^{-/-}$, MIP- $1 \alpha^{-/-}$, and wild-type mice at 14 days after the s.c. or i.v. melanoma cell $\left(1.5 \times 10^{6}\right)$ injection. The amount of IFN- $\gamma$, IL-6, TNF- $\alpha$, and TGF- $\beta$ mRNA was measured by real-time PCR and normalized to the GAPDH endogenous mRNA control. All values represent the mean \pm SEM of results obtained from five to eight mice in each group. ${ }^{*} P<0.05,{ }^{* *} P<0.01$ 


\section{A Spleen}
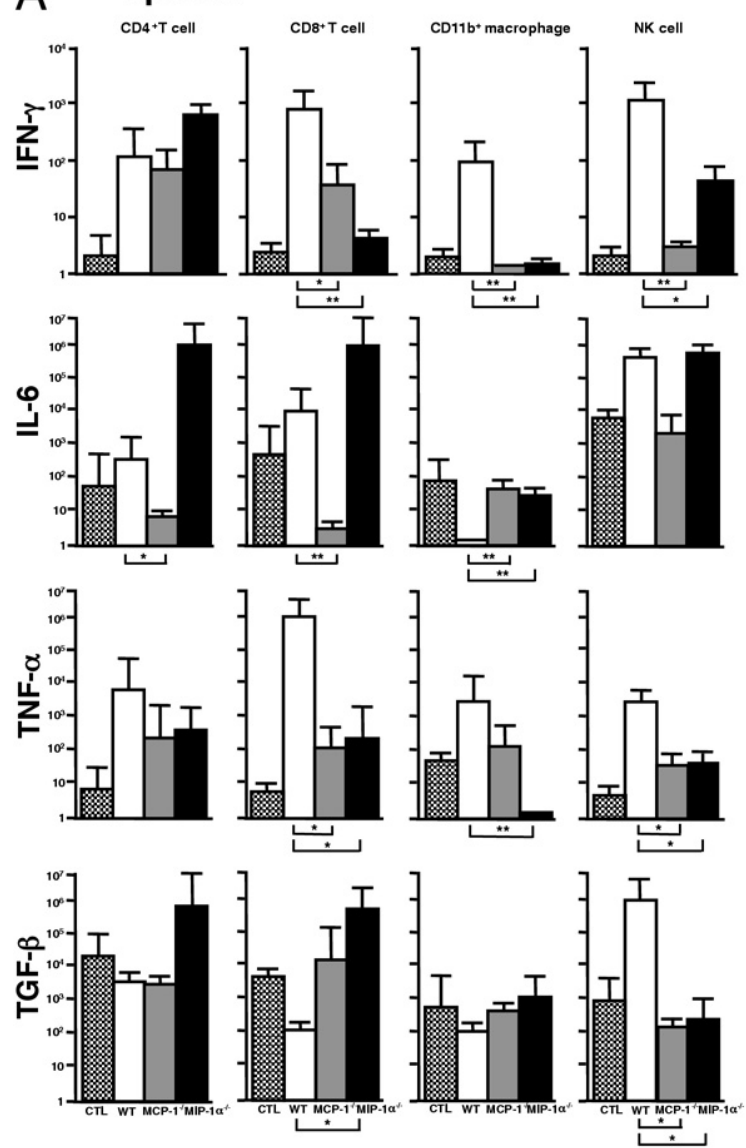

\section{B Peripheral lymph nodes}
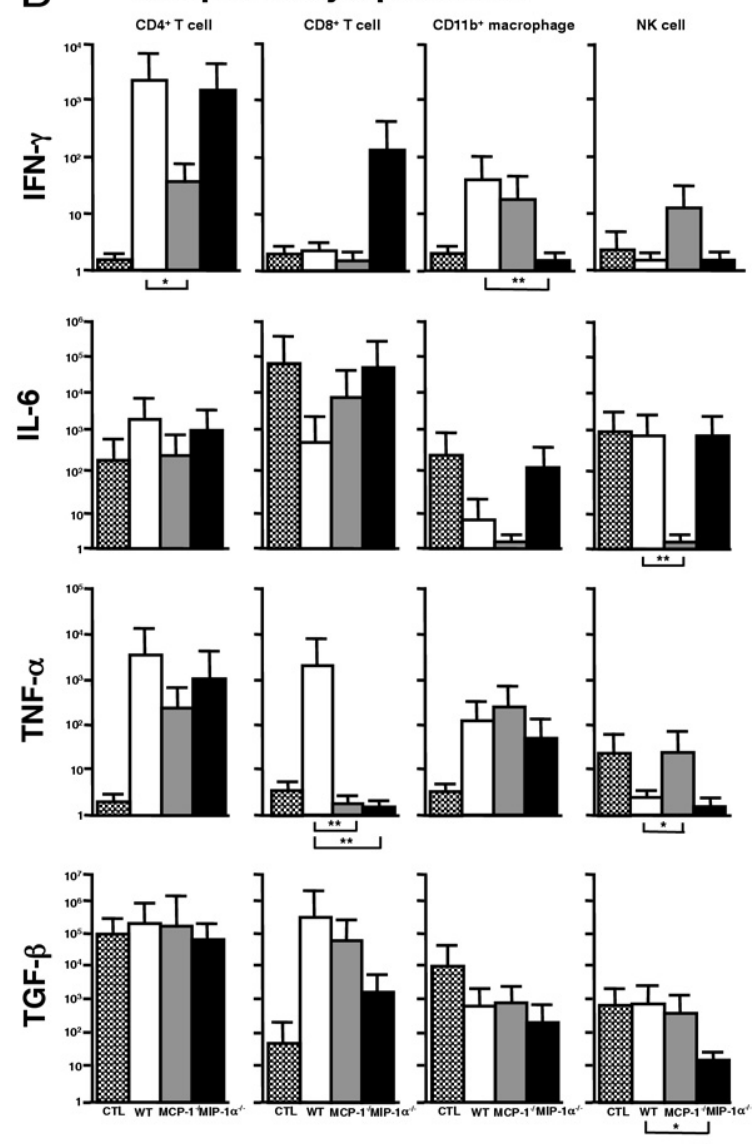

Figure 5. Cytokine mRNA expression in $\mathrm{CD}^{+} \mathrm{T}$ cells, $\mathrm{CD} 8^{+} \mathrm{T}$ cells, NK cells, and macrophages isolated by magnet beads from spleen (A) and peripheral lymph nodes $(\mathbf{B})$ of MCP-1 $1^{-/-}$, MIP-1 $\alpha^{-/-}$, and wild-type mice at 14 days after the i.v. melanoma $\left(1.5 \times 10^{6}\right)$ injection. Wild-type mice after i.v. PBS injection were used for controls (CTLs). The mRNA expression levels of IFN- $\gamma$, IL-6, TNF- $\alpha$, and TGF- $\beta$ mRNA were measured by real-time PCR and normalized to the GAPDH endogenous mRNA control. All values represent the mean \pm SEM of results obtained from five mice in each group. ${ }^{*} P<0.05$, ${ }^{* * *} P<0.01$.

was injected S.c. at the tumor circumference 6 hours after transfer of B16 cells $\left(1.5 \times 10^{6}\right)$ and repeated every other day. After 14 days, the volume of the skin tumor was measured. The injection of MCP-1 or MIP- $1 \alpha$ significantly inhibited the development of primary melanoma $(P<$ 0.05 , Figure $6 A)$. These findings indicate that MCP-1 and MIP-1 $\alpha$ have a suppressive effect for B16 primary melanoma in vivo.

\section{Reduced Primary Tumor Development in Chemokine-Deficient Mice after Cytokine Administration}

The decrease in tumor-associated cytokine expression observed in MCP-1- and MIP- $1 \alpha$-deficient mice suggests a causal link between cytokine production and melanoma development. Therefore, cytokines, including IFN- $\gamma$, IL-6, TNF- $\alpha$, and TGF- $\beta$ (0.1 to $0.15 \mu \mathrm{g})$, were injected S.c. at the tumor circumference 6 hours after transfer of B16 cells and repeated every other day. After 14 days, the volume of the skin tumor was measured (Figure 6B). In wild-type mice, topical injection of IFN- $\gamma$, IL-6, TNF- $\alpha$, or TGF- $\beta$ did not significantly change tumor development compared with PBS-injected controls. By contrast, injection of IFN- $\gamma$ or IL-6 significantly suppressed the development of melanoma in $\mathrm{MCP}_{-1}{ }^{-1-}$ mice $(P<0.01)$. Although the injection of TNF- $\alpha$ or TGF- $\beta$ also reduced the tumor size in MCP- $1^{-1-}$ mice, the effect was not significant. In addition, the injection of IFN- $\gamma$, IL-6, TNF- $\alpha$, or TGF- $\beta$ significantly suppressed the development of primary melanoma in MIP-1 $\alpha^{-1-}$ mice $(P<$ 0.01). Thus, the injection of TGF- $\beta$, TNF- $\alpha$, IFN- $\gamma$, or IL-6 suppressed the development of primary melanoma in $\mathrm{MCP}-1^{-1-}$ mice and MIP- $1 \alpha^{-/-}$mice.

Recovered Expression of Another Chemokine in MCP-1-or MIP-1 $\alpha$-Deficient Mice after Cytokine Administration into the Primary Tumor

The mRNA expression levels of MCP-1 and MIP- $1 \alpha$ were assessed in these cytokine- injected primary melanoma tissues. Although s.c. injection of IFN- $\gamma$, IL-6, TNF- $\alpha$, or TGF- $\beta$ variedly affected the expression of MCP- 1 or MIP- $1 \alpha$, the effect was not significant in the primary tumor of wildtype mice (Figure 6C). The s.c. injection of these cytokines did not induce the expression of MCP-1 in the primary tumor of MCP- $1 \alpha^{-1-}$ mice. Local injection of IFN- $\gamma$, IL-6, and TGF- $\beta$, but not TNF- $\alpha$, induced negligible 


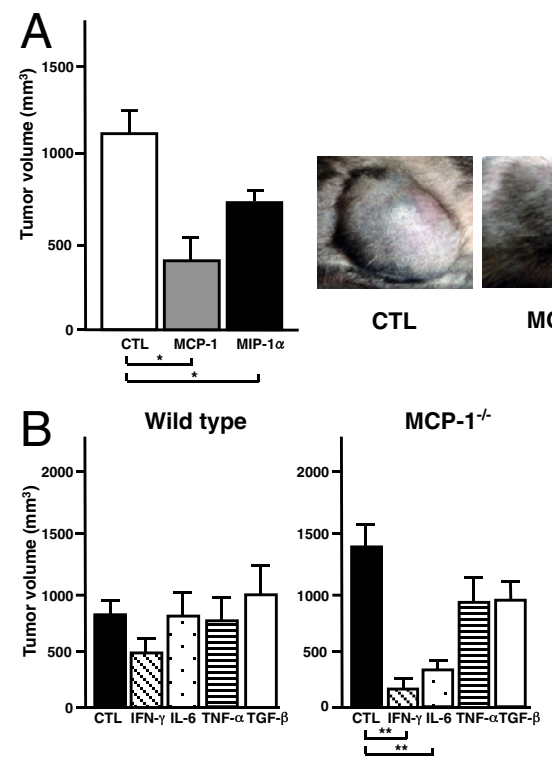

\section{MCP-1 expression}
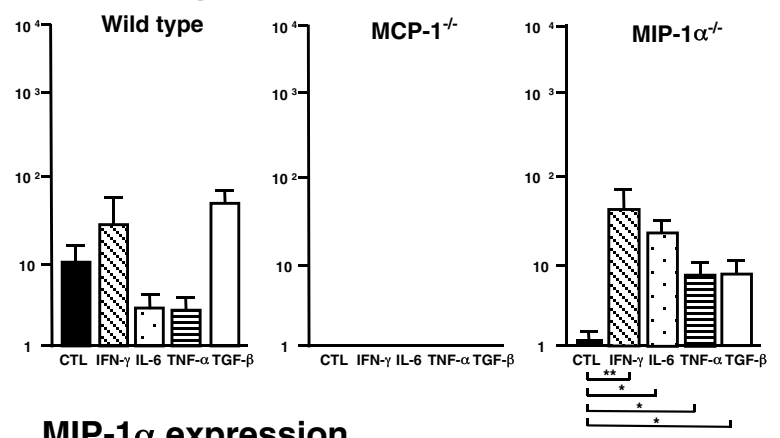

MIP-1 $\alpha$ expression

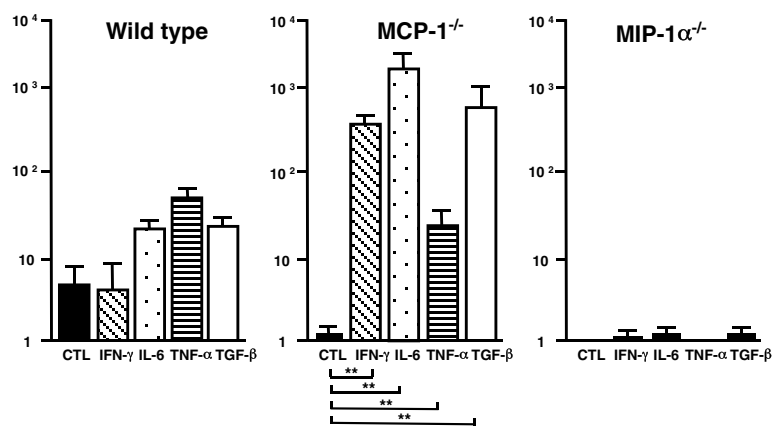

Figure 6. The effect of cytokine injection for primary tumor development and expression of MCP- 1 and MIP- $1 \alpha$. B16 F10 cells $\left(1.5 \times 10^{6}\right)$ in $100 \mu \mathrm{L}$ of PBS were injected s.c. into the shaved lateral flank of mice. Six hours after transfer of B16 F10 cells, the indicated chemokines or cytokines (1.0 to 1.5 $\mu \mathrm{g})$ were injected s.c. at the tumor circumference and repeated every other day thereafter. A: The volumes of primary tumors after s.c. local injection of PBS [controls (CTLs)], recombinant MCP-1, or MIP-1 $\alpha$ were measured on day 14 in wild-type mice. Representative pictures of wild-type mice s.c. injected with PBS, recombinant MCP-1, or recombinant MIP-1 $\alpha$ were shown. B: The volumes of primary tumors. C: mRNA levels of MCP-1 and MIP- $1 \alpha$ were measured on day 14 after s.c. local injection of recombinant cytokines or PBS (CTLs) in mutant and wild-type mice. All values represent the mean \pm SEM. These results were obtained from five mice in each group. ${ }^{*} P<0.05,{ }^{* *} P<0.01$.

expression levels of MIP- $1 \alpha$ in the primary tumor of MIP$1 \alpha^{-1-}$ mice. These findings suggest that B16 melanoma cells do not produce significant amounts of production of MCP-1 or MIP-1 $\alpha$, even after cytokine stimulation. Unexpectedly, MCP-1 expression was diminished in the skin of
MIP- $1 \alpha^{-1-}$ mice. However, the injection of IFN- $\gamma$, IL-6, TNF- $\alpha$, and TGF- $\beta$ significantly increased MCP- 1 expression in the primary tumor of MIP-1 $\alpha^{-/-}$mice $(P<0.05)$. MIP- $1 \alpha$ expression was also markedly reduced in the skin of $\mathrm{MCP}-1^{-1-}$ mice. However, injection of IFN- $\gamma$, IL-6, TNF- $\alpha$, and TGF- $\beta$ significantly increased MIP- $1 \alpha$ expression in the s.c. tumor of MCP-1 $1^{-1-}$ mice $(P<0.05)$. Thus, cytokine injection stimulates the expression of another chemokine, probably from melanoma-infiltrating cells, if the host does not have MCP- 1 or MIP- $1 \alpha$ expression.

\section{Discussion}

To our knowledge, this is the first report showing a critical in vivo role for host-derived chemokines in the progression and metastasis of B16 melanoma using gene-targeted chemokine-deficient mice. In the present study, the primary cutaneous growth, metastasis to the lung, and death from melanoma were augmented by the loss of MCP-1 or MIP-1 $\alpha$ (Figures 1 and 2). The enhancement of primary tumor or metastatic lung tumor outgrowth was generally associated with a reduced accumulation of infiltrating cells, such as $\mathrm{CD}^{+}$and $\mathrm{CD}^{+}{ }^{+} \mathrm{T}$ cells and NK cells (Figure 3 ). In addition, we observed a reduced expression of cytokines, including IFN- $\gamma$, IL-6, TNF- $\alpha$, and TGF- $\beta$ (Figure 4), within B16 tumors, although the expression profile of each cytokine varied between primary tumors and lung metastases and between MCP$1^{-1-}$ mice and MIP- $1 \alpha^{-1-}$ mice. In the primary tumor model, S.c. injection of MCP-1 and MIP- $1 \alpha$ significantly inhibited the development of primary tumor (Figure 6A). Although it remains unclear under which circumstances inflammation contributes to protective anti-tumor immunity or promotes tumor progression, our results indicate that local leukocyte recruitment in response to the hostderived $\mathrm{CC}$ chemokines MCP-1 and MIP-1 $\alpha$ generally leads to anti-melanoma immune responses and increased survival.

Our results demonstrate that the loss of $\mathrm{MCP}-1$ or MIP- $1 \alpha$ significantly promoted the growth of primary tumors and lung metastases (Figures 1 and 2). The relative contribution of MCP-1 and MIP- $1 \alpha$ to the anti-tumor immune response appears to vary between primary sites and metastasis or according to the site of tumor growth. In the primary tumors, the loss of MCP-1 significantly inhibited the infiltration of NK cells, whereas the loss of MIP- $1 \alpha$ significantly inhibited the infiltration of $\mathrm{CD}^{+}{ }^{+} \mathrm{T}$ cells, CD8 ${ }^{+} \mathrm{T}$ cells, and NK cells (Figure 3A). The loss of either MCP-1 or MIP- $1 \alpha$ significantly inhibited the infiltration of $\mathrm{CD}^{+} \mathrm{T}$ cells, CD8 ${ }^{+} \mathrm{T}$ cells, and NK cells in the lungs (Figure 3B). Cancer-related inflammation can directly or indirectly promote tumor formation by enhancing the proliferation and survival of tumor cells, promoting angiogenesis and metastasis, and subverting adaptive immune responses. ${ }^{2,22}$ However, in general, NK cells and $\mathrm{CD}^{+}$cytotoxic $\mathrm{T}$ cells play a crucial role in antitumor immunity. ${ }^{8,23}$ In addition, many studies ${ }^{10,24}$ have shown that $\mathrm{CD}^{+} \mathrm{T}$ cells are needed in the effector phase of the anti-tumor immune response. For example, mice deficient for $\mathrm{CD}^{+}{ }^{+} \mathrm{T}$ cells are unable to reject tumor 
challenges, ${ }^{10,24}$ and activated CD4 ${ }^{+} \mathrm{T}$ cells are present in regressing primary melanomas. ${ }^{25}$ However, it is also well-known that a subpopulation of $\mathrm{CD}^{+} \mathrm{T}$ cells, including regulatory T cells, has protective roles for tumor. ${ }^{3}$ The roles of macrophages in anti-tumor immunity are also complex. Macrophage infiltration correlates with tumor stage and angiogenesis in human malignant melanoma, ${ }^{26}$ and these tumor-associated macrophages secrete cytokines and growth factors mediating the genesis or stasis of endothelial cells that either inhibit or support tumor progression. ${ }^{3}$ Tumor-associated macrophages can also kill tumor cells after being activated by IL-2, IL-12, and IFN- $\gamma^{27,28}$ By contrast, a recent study ${ }^{29} \mathrm{dem}-$ onstrated that $\mathrm{CD} 11 \mathrm{~b}^{+}$macrophages (recruited macrophages), but not $\mathrm{CD} 11 \mathrm{c}^{+}$macrophages (lung resident macrophages), are primary deliverers of tumors, especially in lung metastasis. In the current study, only $\mathrm{CD}_{11 \mathrm{C}^{+}}$macrophages were significantly reduced in the lung metastasis tissues of MCP- $1^{-1-}$ or MIP- $1 \alpha^{-/-}$mice (Figure 3). A comprehensive multivariate analysis of cellular interactions in the tumor microenvironment, based on the type, density, localization, and function of immune cells present within human colorectal cancer, demonstrated that immune reactivity at the tumor site influences clinical outcome. ${ }^{30,31}$ Thus, although the circumstances in which tumor-infiltrating leukocytes either suppress or enhance tumor development remain unclear, our results suggest that $\mathrm{CD} 4^{+} \mathrm{T}$ cells, $\mathrm{CD} 8^{+} \mathrm{T}$ cells, and $\mathrm{NK}$ cells are cooperatively involved in anti-melanoma immune responses.

Loss of MCP-1 and MIP- $1 \alpha$ had differential effects on cytokine expression in the local primary tumor environment (Figure 4A). The loss of MCP-1 significantly inhibited the expression of IL-6, TNF- $\alpha$, and TGF- $\beta$, whereas MIP- $1 \alpha$ deficiency significantly suppressed IFN- $\gamma$, TNF- $\alpha$, and TGF- $\beta$. TGF- $\beta$, in particular, was almost completed absent in MIP- $1 \alpha$-null mice. In addition, IFN- $\gamma$ expression in the metastatic lung was also severely compromised in MCP- $1^{-1-}$ mice (Figure 4B), whereas IL-6 and TGF- $\beta$ were remarkably reduced in MIP- $1 \alpha^{-1-}$ mice. Thus, the loss of MCP-1 or MIP- $1 \alpha$ inhibited the cytokine expression differentially in the s.c. primary site and metastatic lungs, likely because of differential recruitment of minor leukocyte subsets, even though the major leukocyte subsets were similar.

Many studies ${ }^{32}$ have shown that IFN- $\gamma$ inhibits tumor cell growth directly; for example, IFN- $\gamma$ induced cell cycle arrest and/or TNF receptor family-related apoptosis by enhancing CD95/FasL death mechanisms in B16 melanoma. Inconsistent with these previous findings, IFN- $\gamma$ injection inhibited the growth of primary melanoma in wild-type mice, although this was not significant (Figure $6 B)$. In addition, the inhibitory effect was prominent in mice deficient for MCP-1 or MIP- $1 \alpha$. In the lung metastasis model, IFN- $\gamma$ expression on splenocytes was markedly reduced in chemokine-deficient mice and was inversely associated with the severity of lung metastasis (Figures 1B and 5). Therefore, MCP-1 and MIP- $1 \alpha$ may suppress the development of melanoma, at least partially, by recruiting and activating IFN- $\gamma$-producing cells in lymphoid tissues and primary or metastatic tumor sites.
On the other hand, the effect of TNF- $\alpha$, IL-6, and TGF- $\beta$ on tumor progression is not so clear. Like IFN- $\gamma$, TNF- $\alpha$ can bind to the death receptor and can induce apoptosis through adaptor molecules. ${ }^{33}$ However, previous studies ${ }^{34,35}$ have shown that inappropriate TNF- $\alpha$ expression promotes the progression of melanomas and stimulates the migration and invasion of B16 melanoma, whereas anti-TNF- $\alpha$ Ab reduces metastasis to the lung. In the current study, tumor growth and metastasis were associated with reduced TNF- $\alpha$ expression in the tumor lesions and spleen of mutant mice (Figures 4 and 5). However, the local injection of TNF- $\alpha$ ameliorated the expansion of primary s.c. melanoma just in MIP- $1 \alpha^{-/-}$ mice but not in wild-type mice and $\mathrm{MCP}-1^{-1-}$ mice. These findings suggest that TNF- $\alpha$ shows a complicating effect for melanoma according to the microenvironment in vivo. Previous studies ${ }^{36,37}$ have shown that IL-6 inhibits the in vitro growth of early-stage melanoma and promotes the proliferation of cells derived from advanced-stage melanoma. However, IL-6 gene ablation reduced the tumor incidence and tumor size in transgenic mice that develop spontaneous melanoma. ${ }^{38}$ In our study, reduction of IL-6 expression on leukocytes from spleen or peripheral lymph nodes was not necessarily associated with melanoma development (Figure 5). Although IL-6 injection inhibited the primary tumor development in mutant mice, it was not effective for wild-type mice. Finally, TGF- $\beta$ may act as either a tumor suppressor, through its broad antiproliferative potential, or a tumor promoter, either directly on tumor cell aggressiveness or indirectly by modulating stromal responses, angiogenesis, and immune surveillance. ${ }^{39}$ In addition, TGF- $\beta$ is considered a potent tumor suppressor during the early stages of carcinogenesis. ${ }^{40}$ TGF- $\beta$ may also exert tumor promoter activities by promoting the tumor growth, influencing the microenvironment, and contributing peritumor angiogenesis at later stages of carcinogenesis. ${ }^{41}$ The results presented herein (Figure 5) could not determine the definitive function of TGF- $\beta$, IL- 6 , and TNF- $\alpha$ in melanoma progression, probably promoting or inhibiting the tumor growth, dependent on the microenvironment. Nonetheless, these cytokines may function as anti-tumor for primary melanoma in the environment with modest inflammation, such as MCP-1 $1^{-1-}$ or MIP- $1 \alpha^{-1-}$ mice.

Interestingly, S.C. injection of MCP-1 and MIP- $1 \alpha$ significantly suppressed the development of primary melanoma (Figure 6A). The s.c. injection of IFN- $\gamma$, IL-6, TNF- $\alpha$, and TGF- $\beta$ did not significantly augment the expression of MCP- 1 and MIP- $1 \alpha$ in the s.c. tumor of wild-type mice (Figure 6C). Surprisingly, MCP-1 expression in the primary tumor of MIP- $1 \alpha^{-/-}$mice and MIP- $1 \alpha$ expression in the tumor of $\mathrm{MCP}_{-1} 1^{-1-}$ mice were almost completely absent. This may reflect the reduced inflammatory cells that can produce another chemokine in each chemokinedeficient mice. The s.c. injection of IFN- $\gamma$, IL-6, TNF- $\alpha$, and TGF- $\beta$ significantly enhanced the MCP-1 expression in the primary tumor of MIP- $1 \alpha^{-1-}$ mice and MIP- $1 \alpha$ expression in the tumor of $\mathrm{MCP}_{-} 1^{-1-}$ mice. It is unlikely that these cytokines stimulated the expression of chemokines on melanoma cells, because significant expression of MCP-1 and MIP- $1 \alpha$ was not induced on the primary tumor 
of mice deficient for MCP- 1 and MIP- $1 \alpha$, respectively. A previous study ${ }^{42}$ also demonstrated that B16 F10 melanoma did not produce MCP-1. Therefore, our results suggest that cytokines stimulate the expression of MCP-1 and MIP- $1 \alpha$ on melanoma-infiltrating cells. It is possible that augmented MCP- 1 or MIP- $1 \alpha$ expression by cytokine injection may inhibit the tumor growth by recovering the inflammation in addition to the direct effect of cytokine in mutant mice. These findings suggest that recombinant MCP-1 and MIP- $1 \alpha$ or another therapeutic strategy to up-regulate these chemokines may be effective for the treatment of human primary melanoma. However, further studies will be needed to confirm this, because the effect may be different, dependent on the tumor line, timing, and the microenvironment.

In this study, we focused on the function of host-derived chemokines in melanoma progression. In contrast, most previous studies focused on chemokines directly secreted by tumor cells. MCP-1 overexpression in B16 melanoma cells resulted in melanoma cell aggregates infiltrated with twice the number of macrophages as controls. This model suggests that the macrophages inhibited tumor growth and increased survival. ${ }^{43}$ However, when lower concentrations of MCP-1-overexpressing cells were used, tumor progression was increased. ${ }^{43} \mathrm{An}$ additional study ${ }^{44}$ revealed an MCP-1 dose dependency on melanoma progression; low MCP-1 expression from melanoma cells led to low macrophage infiltration and tumor growth promotion, whereas high-level expression attracted many macrophages and had tumoristatic effects. These studies suggest a biphasic role for MCP-1 in tumor progression, dependent on the secretion levels of MCP-1. The injection of B16 melanoma cells transfected with MIP- $1 \alpha$ resulted in reduced pulmonary metastasis by inducing inflammation. ${ }^{17}$ The coexpression of MIP-1 $\alpha$ with a cytotoxic gene was able to significantly increase protection against subsequent B16 melanoma rechallenge. ${ }^{16}$ However, the present study demonstrates that MCP- 1 and MIP- $1 \alpha$, produced by cells other than the melanoma itself, play an important part in anti-tumor responses. Although the cell line we used did not express significant MCP-1 or $\mathrm{MIP}-1 \alpha$, melanoma expressing these chemokines may exhibit different results.

The genetic background of transgenic mice is especially important in a study of tumor immunity. We used MCP- $1^{-1-}$ mice and MIP- $1 \alpha^{-1-}$ mice backcrossed a total of 10 times with C57BL/6J. Statistically, after 10 generations of backcrossing, the congenic and inbred background stains are $99.9 \%$ similar at all unlinked loci, although the region surrounding the introduced gene contains approximately 10 centimorgans of residual donor DNA. Therefore, it is highly unlikely that significant development of melanoma in deficient mice for MCP-1 or MIP- $1 \alpha$ is because of their background. Inconsistent with this, s.C. injection of recombinant MCP-1 or MIP- $1 \alpha$ significantly suppressed the development of primary melanoma (Figure 6A).

Chemokines produced by the immune system are likely functionally linked to the tumor microenvironment. The biological outcome of the chemokine response would, therefore, depend on whether the recruited infil- trating cells are capable of tumor cell killing or whether they promote tumor metastasis through the release of factors that facilitate the intravasation of tumor cells into the vascular system. Further studies will be needed to investigate chemokine function in tumor responses, and careful consideration should be given to the use of chemokines as a therapeutic strategy in human melanoma.

\section{Acknowledgments}

We thank Masako Matsubara and Yuko Yamada for technical assistance.

\section{References}

1. Steeg PS: Metastasis suppressors alter the signal transduction of cancer cells. Nat Rev Cancer 2003, 3:55-63

2. Mantovani A, Allavena P, Sica A, Balkwill F: Cancer-related inflammation. Nature 2008, 454:436-444

3. Grivennikov SI, Greten FR, Karin M: Immunity, inflammation, and cancer. Cell 2010, 140:883-899

4. Dunn GP, Old LJ, Schreiber RD: The immunobiology of cancer immunosurveillance and immunoediting. Immunity 2004, 21:137-148

5. Lin WW, Karin M: A cytokine-mediated link between innate immunity, inflammation, and cancer. J Clin Invest 2007, 117:1175-1183

6. Moore RJ, Owens DM, Stamp G, Arnott C, Burke F, East N, Holdsworth H, Turner L, Rollins B, Pasparakis M, Kollias G, Balkwill F: Mice deficient in tumor necrosis factor-alpha are resistant to skin carcinogenesis. Nat Med 1999, 5:828-831

7. Benamouzig R, Yoon H, Little J, Martin A, Couturier D, Deyra J, Coste T, Chaussade S: APACC, a French prospective study on aspirin efficacy in reducing colorectal adenoma recurrence: design and baseline findings. Eur J Cancer Prev 2001, 10:327-335

8. Burke S, Lakshmikanth T, Colucci F, Carbone E: New views on natural killer cell-based immunotherapy for melanoma treatment. Trends Immunol 2010, 31:339-345

9. Vujanovic L, Butterfield LH: Melanoma cancer vaccines and antitumor T cell responses. J Cell Biochem 2007, 102:301-310

10. Hung K, Hayashi R, Lafond-Walker A, Lowenstein C, Pardoll D, Levitsky $\mathrm{H}$ : The central role of CD4(+) T cells in the antitumor immune response. J Exp Med 1998, 188:2357-2368

11. Allavena P, Sica A, Garlanda C, Mantovani A: The Yin-Yang of tumorassociated macrophages in neoplastic progression and immune surveillance. Immunol Rev 2008, 222:155-161

12. Balkwill F: Cancer and the chemokine network. Nat Rev Cancer 2004 , 4:540-550

13. Somasundaram R, Herlyn D: Chemokines and the microenvironment in neuroectodermal tumor-host interaction. Semin Cancer Biol 2009, 19:92-96

14. Oppenheim JJ, Zachariae CO, Mukaida N, Matsushima K: Properties of the novel proinflammatory supergene "intercrine" cytokine family. Annu Rev Immunol 1991, 9:617-648

15. Luther SA, Cyster JG: Chemokines as regulators of T cell differentiation. Nat Immunol 2001, 2:102-107

16. Crittenden M, Gough M, Harrington K, Olivier K, Thompson J, Vile RG: Expression of inflammatory chemokines combined with local tumor destruction enhances tumor regression and long-term immunity. Cancer Res 2003, 63:5505-5512

17. van Deventer HW, Serody JS, McKinnon KP, Clements C, Brickey WJ, Ting JP: Transfection of macrophage inflammatory protein 1 alpha into B16 F10 melanoma cells inhibits growth of pulmonary metastases but not subcutaneous tumors. J Immunol 2002, 169:1634-1639

18. Lu B, Rutledge BJ, Gu L, Fiorillo J, Lukacs NW, Kunkel SL, North R, Gerard C, Rollins BJ: Abnormalities in monocyte recruitment and cytokine expression in monocyte chemoattractant protein 1-deficient mice. J Exp Med 1998, 187:601-608 
19. Cook DN, Beck MA, Coffman TM, Kirby SL, Sheridan JF, Pragnell IB, Smithies O. Requirement of MIP-1 alpha for an inflammatory response to viral infection. Science 1995, 269:1583-1585

20. Meijerink J, Mandigers C, van de Locht L, Tonnissen E, Goodsaid F Raemaekers J: A novel method to compensate for different amplification efficiencies between patient DNA samples in quantitative realtime PCR. J Mol Diagn 2001, 3:55-61

21. Balkwill F, Mantovani A. Inflammation and cancer: back to Virchow? Lancet 2001, 357:539-545

22. Rollins BJ: Inflammatory chemokines in cancer growth and progression. Eur J Cancer 2006, 42:760-767

23. Mantovani A, Romero P, Palucka AK, Marincola FM: Tumour immunity: effector response to tumour and role of the microenvironment. Lancet 2008, 371:771-783

24. Dranoff G, Jaffee E, Lazenby A, Golumbek P, Levitsky H, Brose K, Jackson V, Hamada H, Pardoll D, Mulligan RC: Vaccination with irradiated tumor cells engineered to secrete murine granulocytemacrophage colony-stimulating factor stimulates potent, specific, and long-lasting anti-tumor immunity. Proc Natl Acad Sci U S A 1993 90:3539-3543

25. Tefany FJ, Barnetson RS, Halliday GM, McCarthy SW, McCarthy WH: Immunocytochemical analysis of the cellular infiltrate in primary regressing and non-regressing malignant melanoma. J Invest Dermatol 1991, 97:197-202

26. Torisu H, Ono M, Kiryu H, Furue M, Ohmoto Y, Nakayama J, Nishioka $Y$, Sone S, Kuwano M: Macrophage infiltration correlates with tumor stage and angiogenesis in human malignant melanoma: possible involvement of TNFalpha and IL-1alpha. Int J Cancer 2000, 85:182188

27. Brigati C, Noonan DM, Albini A, Benelli R: Tumors and inflammatory infiltrates: friends or foes? Clin Exp Metastasis 2002, 19:247-258

28. Tsung K, Dolan JP, Tsung YL, Norton JA: Macrophages as effector cells in interleukin 12-induced T cell-dependent tumor rejection. Cancer Res 2002, 62:5069-5075

29. Qian B, Deng Y, Im JH, Muschel RJ, Zou Y, Li J, Lang RA, Pollard JW: A distinct macrophage population mediates metastatic breast cancer cell extravasation, establishment and growth. PLoS One 2009, 4:e6562

30. Galon J, Costes A, Sanchez-Cabo F, Kirilovsky A, Mlecnik B, Lagorce-Pages C, Tosolini M, Camus M, Berger A, Wind P, Zinzindohoue $F$, Bruneval P, Cugnenc PH, Trajanoski Z, Fridman WH, Pages F: Type, density, and location of immune cells within human colorectal tumors predict clinical outcome. Science 2006, 313:1960-1964

31. Pages F, Berger A, Camus M, Sanchez-Cabo F, Costes A, Molidor R, Mlecnik B, Kirilovsky A, Nilsson M, Damotte D, Meatchi T, Bruneval P, Cugnenc PH, Trajanoski Z, Fridman WH, Galon J: Effector memory T cells, early metastasis, and survival in colorectal cancer. $\mathrm{N}$ Engl J Med 2005, 353:2654-2666
32. Krasagakis K, Garbe C, Zouboulis CC, Orfanos CE: Growth control of melanoma cells and melanocytes by cytokines. Recent Results Cancer Res 1995, 139:169-182

33. Nishida S, Yoshioka S, Kinoshita-Kimoto S, Kotani M, Tsubaki M, Fujii $\mathrm{Y}$, Tomura TT, Irimajiri K: Pretreatment with PKC inhibitor triggers TNF-alpha induced apoptosis in TNF-alpha-resistant B16 melanoma BL6 cells. Life Sci 2003, 74:781-792

34. Waterston AM, Salway F, Andreakos E, Butler DM, Feldmann M, Coombes RC: TNF autovaccination induces self anti-TNF antibodies and inhibits metastasis in a murine melanoma model. $\mathrm{Br} \mathrm{J}$ Cancer 2004, 90:1279-1284

35. Zhu N, Lalla R, Eves P, Brown TL, King A, Kemp EH, Haycock JW, MacNeil S: Melanoma cell migration is upregulated by tumour necrosis factor-alpha and suppressed by alpha-melanocyte-stimulating hormone. Br J Cancer 2004, 90:1457-1463

36. Florenes VA, Lu C, Bhattacharya N, Rak J, Sheehan C, Slingerland JM, Kerbel RS: Interleukin-6 dependent induction of the cyclin dependent kinase inhibitor p21WAF1/CIP1 is lost during progression of human malignant melanoma. Oncogene 1999, 18:1023-1032

37. Lu C, Vickers MF, Kerbel RS: Interleukin 6: a fibroblast-derived growth inhibitor of human melanoma cells from early but not advanced stages of tumor progression. Proc Natl Acad Sci U S A 1992, 89:9215-9219

38. von Felbert V, Cordoba F, Weissenberger J, Vallan C, Kato M, Nakashima I, Braathen LR, Weis J: Interleukin-6 gene ablation in a transgenic mouse model of malignant skin melanoma. Am J Pathol 2005, 166:831-841

39. Javelaud D, Alexaki VI, Mauviel A: Transforming growth factor-beta in cutaneous melanoma. Pigment Cell Melanoma Res 2008, 21:123-132

40. Massague J, Gomis RR: The logic of TGFbeta signaling. FEBS Lett 2006, 580:2811-2820

41. Leivonen SK, Kahari VM: Transforming growth factor-beta signaling in cancer invasion and metastasis. Int J Cancer 2007, 121:2119-2124

42. Stathopoulos GT, Psallidas I, Moustaki A, Moschos C, Kollintza A, Karabela S, Porfyridis I, Vassiliou S, Karatza M, Zhou Z, Joo M, Blackwell TS, Roussos C, Graf D, Kalomenidis I: A central role for tumor-derived monocyte chemoattractant protein-1 in malignant pleural effusion. J Natl Cancer Inst 2008, 100:1464-1476

43. Bottazzi B, Walter S, Govoni D, Colotta F, Mantovani A: Monocyte chemotactic cytokine gene transfer modulates macrophage infiltration, growth, and susceptibility to IL-2 therapy of a murine melanoma. J Immunol 1992, 148:1280-1285

44. Nesbit M, Schaider H, Miller TH, Herlyn M: Low-level monocyte chemoattractant protein-1 stimulation of monocytes leads to tumor formation in nontumorigenic melanoma cells. J Immunol 2001, 166: 6483-6490 